\title{
Extravagancia estatal: Construcción de Estado e inserción en el siglo XXI, caso Yemen (1990-2011)*
}

RUBÉN DARÍO GARCÍA ESCOBAR**

Artículo recibido: 4 de octubre de 2016

Artículo aprobado: 14 de diciembre de 2016

Doi: http://dx.doi.org/10.12804/revistas.urosario.edu.co/desafios/a.5203

Para citar este artículo: García, R. D. (2017). Extravagancia estatal: Construcción de Estado e inserción en el siglo XXI, caso Yemen (1990-2011). Desafíos, 29(2). 127-167. doi: http:/ / dx.doi.org/10.12804/revistas.urosario.edu.co/desafios/a.5203

\section{Resumen}

Han transcurrido cerca de veinte años desde la primera publicación del trabajo más simbólico del realismo subalterno, The Third World Security Predicament de $M$. Ayoob; un cuarto de siglo después la finalización de la Guerra Fría se ha atestiguado una serie de trasformaciones en la politica mundial, al igual que ciertas continuidades. La construcción de Estado y la inserción en el sistema internacional-punto de partida del enfoque subalterno para la comprensión del comportamiento estatal en el Tercer Mundo-, como procesos sociales, están sujetos a constantes transformaciones que incidirán en el comportamiento estatal. En el momento en que se escribe este articulo ba sucedido una serie de eventos que permiten poner en perspectiva el realismo subalterno de M. Ayoob: Yemen, como parte integrante del Tercer Mundo, se muestra como un caso pertinente para realizar esta revisión.

Palabras clave: realismo subalterno, Sociedad de Estados, construcción de Estado, inserción, Yemen

\footnotetext{
* Este artículo es resultado de la monografía de grado en la Maestría en Estudios Políticos e Internacionales en la Universidad del Rosario llamada Predicamento de seguridad yemení (1990-2011). ** Ex estudiante de la Maestría en Estudios Políticos e Internacionales de la Universidad del Rosario, Bogotá. Correo electrónico: garcia.es.ruben@gmail.com. ORCID: http:/ /orcid. org/0000-0001-5829-1996
} 


\title{
States' Outlandishness: State Making and Insertion in the XXI century, Yemen (1990-2011)
}

\begin{abstract}
Twenty years have passed since the publication of the foundational text of subaltern realism, "The Third World Security Predicament" by Mohammed Ayoob. Since the end of the Cold War, we have witnessed a number of transformations, but also some important continuities in world politics. State-building processes and forms of insertion into the international system are subject to constant changes that have an influence on state behavior. This article provides a historical perspective on subaltern realist theory through the study of state-building and internal conflict in Yemen from 1990 to 2011 in form of an "ideal case study".
\end{abstract}

Keywords: Subaltern realism, state-making, international society, Yemen

\section{Extravagância estatal: Construção de Estado e inserção no século XXI, caso lémen (1990-2011)}

\begin{abstract}
Resumo
Têm transcorrido cerca de vinte anos desde a primeira publicação do trabalho mais simbólico do Realismo Subalterno, The Third World Security Predicament de M. Ayoob; um quarto de século depois da finalização da Guerra Fria se tem testificado uma série de transformacões na politica mundial, da mesma forma que certas continuidades. A construção de Estado e a inserção ao Sistema Internacional, ponto de partida do enfoque subalterno para a compreensão do comportamento estatal no Terceiro Mundo, como processos sociais, estão sujeitos a constantes transformações que incidirão no comportamento estatal. No momento em que escreve-se este artigo têm acontecido uma série de eventos que permitem pôr em perspetiva o Realismo Subalterno de M. Ayoob; Iémen, como parte integrante do Terceiro Mundo mostra-se como um caso pertinente para realizar esta revisão.

Palavras-chave: realismo Subalterno, Sociedade de Estados, construção de Estado, inserção, Iémen
\end{abstract}




\section{Introducción}

A lo largo de las últimas décadas se ha presentado una serie de sucesos que han conducido a que se refuerce la noción de turbulencia ${ }^{1}$ en el sistema: desorden e impredictibilidad. Además de dar prioridad a la guerra y al poder, conceptos clave de paradigmas tradicionales y objeto de estudio predilectos (Beitz, 1999), esta característica del sistema ha eclipsado el incremento del componente sociedad durante lo corrido del periodo pos Guerra Fría. Estos dos argumentos (turbulencia e incremento del componente sociedad) se presentaron como punto de partida para la investigación a partir de la cual surge este artículo y en el cual se busca dar respuesta a la siguiente pregunta: ¿Cómo influyeron los procesos de construcción de Estado e inserción al sistema en la crisis política que atravesó Yemen durante las revueltas árabes en 2011?

Los procesos mencionados en la pregunta de investigación fueron seleccionados como las variables independientes ${ }^{2}$ sobre las cuales esta se desarrolló. Son sugeridas por M. Ayoob (1995) como aquellas que se acomodan más para la comprensión del comportamiento estatal en el Tercer Mundo a partir del realismo subalterno. Yemen cumple con las características conceptuales que ayudan a identificar a un Estado como parte del Tercer Mundo: pasado colonial, desarrollo distorsionado y dependiente, marginación frente a la Sociedad de Estados y a las acciones de carácter colectivo, contar con bajos niveles de legitimidad y ser fácilmente permeable a factores externos.

Además de cumplir estos criterios, el estudio de la República de Yemen pareció apropiado para la investigación por haber participado de algunas de las principales tendencias que han caracterizado el actual periodo: creación de un nuevo Estado en el año 1991 ya que, luego de la exis-

\footnotetext{
1 La turbulencia hace referencia a una propiedad del sistema según la cual existen altos niveles de interacción y una gran diversidad de actores (Rosenau, 1990).

2 Independientes no quiere decir que las variables puedan ser aisladas o descontextualizadas. A lo largo de la investigación se muestra cómo responden a condiciones históricas particulares en diversas escalas.
} 
tencia de dos estados yemenís por casi cuatro décadas, se lleva a cabo un proceso de unificación estatal; guerra civil como parte de la construcción de Estado y la consolidación de la unificación estatal pues, en el año 1994, se libra una guerra entre la élite estatal del sur y del norte del país; reformas económicas y estructurales iniciadas en 1995 con el objetivo de organizar un país que pudiera responder a la realidad de un sistema capitalista global; participación activa en la guerra contra el terrorismo en el cual la élite estatal fue un actor fundamental en la lucha contraterrorista y en la que ciertas regiones del país se consolidaron como puntos geoestratégicos para el mantenimiento de la seguridad y orden mundial; fue uno de los países que se vio involucrado en los sucesos regionales de la revueltas árabes en 2011.

La investigación partió del realismo subalterno para analizar el comportamiento del Estado yemení y la relación del predicamento de seguridad con la crisis política de 2011. La hipótesis inicial, de acuerdo a los postulados teóricos subalternos, consistía en que las variables independientes (construcción de Estado e inserción) como procesos políticos emprendidos por la élite estatal efectivamente contribuyeron a la consolidación de las condiciones en las cuales se daría la crisis política de 2011. Dados los tempranos estadios en los que se encontraba el Estado en estos procesos, las principales amenazas a su seguridad se originaban en su interior, es decir que existía una mayor propensión al conflicto por parte de la élite estatal frente a la población, y el escenario internacional se mostraba como un espacio a partir del cual obtener recursos aunque fuera de manera condicionada.

Una vez claro el caso de investigación y seleccionado el marco teórico, la metodología a seguir consistió en la recolección de fuentes empíricas secundarias sobre Yemen para iniciar un proceso de análisis de acuerdo a los principios teóricos del realismo subalterno para dar respuesta a la pregunta de investigación. A partir del contraste entre la evidencia empírica y los aportes teóricos subalternos, se realizó una revisión de este enfoque que condujo a ciertas conclusiones que serán expuestas a lo largo del artículo. 
Este se divide en cuatro partes que corresponden a: exposición de los principios teóricos del realismo subalterno, de la operatividad de variables independientes y puesta en perspectiva frente a las principales tendencias que han caracterizado el periodo de pos Guerra Fría; análisis del predicamento de seguridad yemení durante los periodos 1990-2000 y 2001-2011; examen de la relación que tienen los procesos de construcción de Estado e inserción frente a la crisis política de 2011; finalmente, unas conclusiones respecto al realismo subalterno y su aporte para la relaciones internacionales.

\section{Realismo subalterno en perspectiva}

Aunque este no es un espacio para hacer una descripción a fondo acerca del realismo subalterno, parece necesario mencionar algunos de los postulados que le dan forma para entender el desarrollo de la investigación. El principal argumento del enfoque subalterno, y diferencia fundamental con el realismo tradicional, es que la mayoría de amenazas a la seguridad de los Estados del Tercer Mundo son de carácter interno; las amenazas externas siguen siendo una posibilidad. Este argumento está sustentado por los tempranos estadios en el proceso de construcción de Estado e inserción (Ayoob, 1995, pp. 21-46).

Estos procesos, dados en contextos históricos particulares, determinan la problemática de seguridad y es en torno a ellos que las élites estatales del Tercer Mundo se encuentran enfrascadas en diversas contradicciones. La más evidente es la de llevar a cabo procesos de centralización primarios (desarrollo de niveles adecuados de estatalidad) en medio de un marco normativo que exige la descentralización del poder estatal (derechos humanos, desarrollo, democracia liberal). La segunda contradicción más importante es articulada por M. Ayoob (1989) como la esquizofrenia de las élites estatales: en cuanto acciones colectivas persiguen intereses reivindicativos y como unidades individuales (Estados) su accionar propende hacia el mantenimiento del statu quo. 
El predicamento de seguridad es el resultado de esta situación. Este concepto hace referencia al profundo sentimiento de inseguridad de las élites estatales del Tercer Mundo y se constituye, a partir de sus variables independientes, como el principal factor explicativo del comportamiento de estos Estados.

La inserción fue entendida como un proceso vinculante (voluntario o forzado) mediante el cual un actor inicia un proceso multidimensional para formar parte del sistema internacional de Estados mediante la aceptación de sus principales valores e instituciones ${ }^{3}$. Implica el cumplimiento de ciertos estándares de organización interna y un comportamiento exterior específico. En este se puede identificar una dimensión formal/jurídica correspondiente a los marcos jurídicos y organizacionales y la percepción/acción en la cual el sistema pasa a ser una realidad objetiva a través de las acciones concretas de los actores.

De esta manera un Estado se puede ubicar a lo largo de un continuo inserto-no inserto a partir de un análisis en el cual se incluya la capacidad de la élite estatal de proyectar su interés en la política mundial (política exterior), la participación e influencia en la toma de decisiones de carácter colectivo de manera intencional (relaciones interestatales), la capacidad de modificar la comprensión y comportamientos que se desprenden de los principios de la Sociedad de Estados (constructor de sociedad) y la voluntad y la capacidad que tiene de transgredir normas y otras clases de constreñimientos asumiendo los costos que implica (autonomía).

La construcción de Estado fue comprendida como el proceso mediante el cual una élite política emprende una serie de acciones encaminadas a cimentar una unidad política en cuya estructura se centraliza la vida social de una población específica dentro de un espacio territorial definido. Sus principales funciones son hacer la guerra, el control interno y la extracción de recursos (Ayoob, 1995, pp. 23-26). Para desempeñar dichas funciones es necesario consolidar

\footnotetext{
3 Entendidas en términos de instituciones primarias: valores, comportamientos, entendimientos, reglas y costumbre (Buzan, 2004, pp. 161-204; Knudsen, 2013).
} 
una autonomía frente a la población interna mediante la centralización de los medios de coerción (Tilly, 2006), la administración de valores (Miller, 2013) y la actividad política. El fin último de este proceso es alcanzar niveles adecuados de estatalidad.

La manera en que se operacionaliza este proceso es la identificación de la estrategia de construcción de Estado que predomina durante un periodo específico; aunque las estrategias (políticas públicas) implementadas son muchas e implementadas de manera simultánea, se puede identificar un centro gravitatorio para facilitar el análisis. Para esto usé la división de Miller (2013) de las principales dimensiones del Estado: fuerza de coerción, actor económico, distribuidor de bienes y servicios, materialización de una teoría de la justicia y herramienta para el bienestar humano. A estas fueron agregados los criterios del Estado como constructor de espacios sociales, regulador de comportamientos e intermediario entre lo global y lo local.

A pesar de ser identificados de manera independiente, su aislamiento se da únicamente con fines metodológicos, ya que estos procesos se desarrollan en medio de una constante retroalimentación; sería casi que imposible aislar procesos de construcción de Estado respecto a lo que sucede en la política mundial.

\section{Realismo subalterno y el periodo post Guerra Fría}

La revisión en torno al realismo subalterno tiene como punto de partida el siguiente argumento: El periodo pos Guerra Fría se ha caracterizado por el aumento sustancial del componente "sociedad" del sistema internacional. El sistema actual se distingue por el incremento en los niveles organizativos, de homogenización y de cohesión (Barbe, 2004), en torno a principios de la democracia y de la economía liberal (Amin, 2001). Este componente social, a diferencia del sistémico, se basa en la aceptación de valores y principios de organización. Lo sistémico hace referencia al nivel de interacciones entre unidades (Bull, 2005; Rosenau, 1990; Waltz, 1979).

Este "consenso" ha dado lugar a la homogenización de estructuras organizacionales e ideológicas, propiciando un ambiente adecuado 
para la difusión de ideas y técnicas (Strang y Meyer, 1993), entre las cuales se incluye la difusión de estrategias de construcción de Estado e inserción. En la medida en que se ha fortalecido el Estado como unidad política en torno a la Sociedad de Estados se hace más fácil la difusión de modelos estatales, económicos y diversas formas de organización de la vida social que responden a una visión predominante ${ }^{4}$.

Hablar de un incremento sustancial del componente "sociedad" en el sistema no se presenta como un obstáculo en términos metodológicos u ontológicos frente al realismo subalterno. Si bien M. Ayoob no es muy enfático al respecto, a lo largo de su obra The Third Word Security Predicament hace constantes referencias a este suceso. Resalta el desarrollo histórico del sistema como un proceso de promoción de proyectos estatales a lo largo y ancho del planeta, así como el papel que han tenido el capitalismo y la colonización en la constitución de la actual Sociedad de Estados (Ayoob, 1995).

Junto al argumento respecto al incremento del componente sociedad se encuentran ciertas tendencias que han caracterizado el periodo pos Guerra Fría, como la expansión de valores democráticos, el incremento de regímenes para el control armamentístico, el predominio de temas económicos y la disminución de conflictos interestatales ${ }^{5}$. A partir de esto se estableció una distinción de dos etapas al interior del periodo de pos Guerra Fría desde las variables independientes del predicamento de seguridad.

\footnotetext{
4 En este sentido E. Carr (1946) en su trabajo insignia The twenty years' crisis 1919-1939 sostenía que la política mundial respondía a un ejercicio de autoridad que se manifiesta en exhibir fines particulares (estados dominantes) como universales; el periodo actual podría se entendido como el éxito de dicha estrategia.

5 Estas tendencias fueron más evidentes durante los primeros años del periodo pos Guerra Fría, sin embargo han venido cambiando con especial énfasis desde inicios del siglo XXI (Abbott, Rogers y Slobada, 2006; Nowak, Quirk y XIang, 2014).
} 


\section{Principales características del Predicamento de Seguridad durante el periodo de pos Guerra Fría}

\begin{tabular}{|c|c|c|}
\hline & Década de los noventa & Año 2000 en adelante \\
\hline Inserción & $\begin{array}{l}\text { Promoción procesos } \\
\text { democratización. } \\
\text { Discurso democrático y } \\
\text { desarrollista. } \\
\text { Noción constructores de } \\
\text { Estado externo. } \\
\text { Incremento temáticas en la } \\
\text { configuración de la agenda } \\
\text { internacional. } \\
\text { Relajamiento de la } \\
\text { estructura internacional. }\end{array}$ & $\begin{array}{l}\text { Promoción de Estado } \\
\text { enfocada en la dimensión de } \\
\text { coerción. } \\
\text { Priman temas de seguridad } \\
\text { en la agenda internacional. } \\
\text { Estado fallido o vulnerable } \\
\text { como amenaza a la } \\
\text { seguridad y orden global. } \\
\text { Internacionalización del } \\
\text { predicamento de seguridad. }\end{array}$ \\
\hline Construcción de Estado & $\begin{array}{l}\text { Estado como } \\
\text { materialización de una teoría } \\
\text { de justicia (democracia } \\
\text { liberal). } \\
\text { Perdida de autonomía del } \\
\text { estado en favor de actores } \\
\text { no-soberanos debido al } \\
\text { discurso neoliberal. } \\
\text { Incremento y diversificación } \\
\text { de las formas de liderazgo. } \\
\text { Crisis humanitaria como } \\
\text { la última consecuencia del } \\
\text { fracaso estatal. } \\
\text { Desarrollo como pre- } \\
\text { condición para la seguridad. }\end{array}$ & $\begin{array}{l}\text { Se privilegian estrategias en } \\
\text { el marco de la dimensión } \\
\text { "coerción". } \\
\text { Se refuerzan procesos de } \\
\text { centralización estatal. } \\
\text { Prima el paradigma del } \\
\text { "Estado Fuerte". } \\
\text { Estado como garante de } \\
\text { condiciones adecuadas para } \\
\text { la democracia y el desarrollo. } \\
\text { Incremento de demandas en } \\
\text { seguridad que recaen en el } \\
\text { Estado. }\end{array}$ \\
\hline
\end{tabular}

Fuente: Elaboración propia.

Las siguientes partes del artículo estarán dedicadas a continuar con la revisión del realismo subalterno y, de manera simultánea, analizar el predicamento de seguridad yemení en las dos etapas que han sido establecidas. 


\section{Predicamento de seguridad y cambio: Yemen, un nuevo miembro de la Sociedad de Estados}

La creación de la República de Yemen en el año de 1991 coincide con la finalización de la Guerra Fría. Una de las formas en que puede ser entendido el inicio de este nuevo proyecto estatal es como parte de los intentos de la élite estatal yemení por superar el sentimiento de inseguridad. Si bien al inicio de este nuevo periodo del sistema no se le puede responsabilizar por el estallido de conflictos internos en el Tercer Mundo durante la década de los noventa, sí estableció ciertas condiciones externas que afectaron a este grupo de países, entre ellos Yemen. La élite estatal yemení realizó una serie de acciones que respondían a estas nuevas condiciones que fueron filtradas a través de la política interna.

La unificación de Yemen se da en un momento de trasformación del orden internacional y en medio de condiciones internas particulares. Con anterioridad a este suceso existieron dos estados yemenís: la República Popular y Democrática de Yemen, fundada en 1967, fue la primera nación de orientación marxista en medio oriente (National Review, 1994); y la República Árabe de Yemen que fue creada bajo la ideología del nacionalismo árabe del periodo de descolonización. En el momento de la unificación, acordada para desarrollarse a través de medios políticos, ambos estados se enfrentaban a situaciones internas precarias. En el norte la situación económica había comenzado a generar brotes de inestabilidad política interna y en el sur se vivió una fuerte ola de violencia política durante la década de los ochenta (Ismail, 2014).

Tanto en la etapa inicial que se dio través de medios políticos pacíficos como en su consolidación a través de la violencia con la guerra civil de 1994 (Heibach y Ouaissa, 2015), el proceso de unificación se desarrolló de "arriba hacia abajo", es decir, por las élites estatales; existían condiciones culturales y políticas que lo permitieron. La guerra civil de 1994 fue el punto más álgido del enfrentamiento entre la élite estatal del norte y del sur.

El conflicto interno y la caída de la economía, agravada por las sanciones que produjo la participación de Yemen en el Consejo de Seguridad, 
serían eventos que determinarían la vida política yemení durante los años noventa. Este último se da como una de las primeras experiencias importantes de Yemen al interior de la Sociedad de Estados.

\section{El fin de la ideología y el inicio de la inseguridad}

Con la finalización de la Guerra Fría se inicia el periodo en que las unidades estatales se han visto más homogenizadas a lo largo de la historia del sistema. La democracia, el capitalismo y el desarrollo serían los pilares que darían paso a este hecho. Durante estos años las discusiones en torno al nuevo orden mundial daban a Estados Unidos un papel predominante como la superpotencia sobreviviente a la bipolaridad, idea que perdió validez rápidamente (Abbott, Rogers y Slobada, 2006; Barbe, 2004; Wallerstein, 2007).

Una de las nociones que se construye durante este periodo, en el cual las potencias de Occidente destacaron, fue la de "constructores de Estado externos". Tras la profundización de la tendencia hacia la desregularización y la privatización que se comenzó a gestar en los setenta en torno a la ideología liberal (Cox, 2014), la socialización de los criterios de inserción se concentran más en el desarrollo y en los procesos de democratización. Los esfuerzos en la construcción de Estado y su promoción no se concentran en aspectos primarios sino en el Estado como actor económico (capitalismo y desarrollo) y como materialización de una teoría de la justica (democracia); se transforman en las condiciones necesarias para alcanzar la estabilidad en el Tercer Mundo.

La principal preocupación respecto a aquellos Estados que se encontraban en tempranos estadios de construcción era la catástrofe humanitaria (Mols, 2011). El incremento de conflictos internos, que en buena parte fueron explicados a través de la tesis de la "estabilidad bipolar” (Kim, 2009), contribuyó a aumentar los esfuerzos en la ayuda a favor del desarrollo, la cual fue aportada en un principio casi exclusivamente por las potencias de Occidente (Quirk, 2014). La práctica a través de la cual se hace más evidente la noción de constructor de Estado externo fue, y sigue siendo, la intervención humanitaria y todas aquellas misiones que se dieron en el marco de 
Naciones Unidas denominadas peacemaking, peacekeeping, peacebuilding y peace enforcement (UN-Peacekeeping, s.f). Esta noción también se hace operativa a través de intervenciones directas o indirectas, unilaterales o bilaterales, como las que se han dado en Iraq, Afganistán, Colombia, Siria y muchos otros países en los cuales el objetivo ha sido influenciar el proceso de centralización estatal, pacificación interna y el monopolio del uso de la violencia.

Este entorno tuvo en Yemen unas manifestaciones específicas que se hicieron más evidentes en sucesos como la unificación (1990), la participación yemení como miembro no permanente del Consejo de Seguridad de Naciones Unidas (1991), la guerra civil (1994) y las reformas estructurales a la economía (1995).

La unificación surge como resultado de la negociación entre la RAY (República Árabe de Yemen) y la RDPY (República Democrática Popular de Yemen). Una vez aprobada la unificación a través de un referendo popular inicia un periodo de transición en el que la población logra beneficiarse del establecimiento de ciertas libertades políticas (Carapico, 1993). Acorde con la democracia liberal que operaba como principio de inserción durante los años noventa, se adopta un sistema democrático y multipartidista, muy diferente a lo establecido en borradores constitucionales redactados durante los setenta (Tripoli Agreement, 1972; Cairo Agreement, 1972).

Este giro hacia un sistema más democrático fue uno de los puntos a los cuales llega la elite estatal yemení para la redistribución de poder en el nuevo proyecto estatal que se iniciaba. El desarrollo de la política interna haría que la palabra democratización tomara un sentido diferente a la prosecución del ideal de democracia. Los demás actores de la Sociedad de Estados apoyaron el proceso de unificación estatal; la única excepción fueron Arabia Saudí y algunas monarquías que veían en este nuevo proyecto una plataforma para la propagación de ideas democráticas y republicanas en la región (Katz, 1992; Xia, 2010).

En 1991, Yemen es elegido miembro no permanente del Consejo de Seguridad de Naciones Unidas y durante este momento estalla 
la Guerra del Golfo. La posición que tomó la élite estatal yemení al interior de la organización fue la de no apoyar la intervención y buscar una solución negociada respetando los principios de no intervención, autodeterminación y diplomacia. La reacción de Occidente y los países del Golfo fue negativa, lo que reflejó la distinción entre la dimensión jurídica/formal, a la cual la élite yemení se trató de apegar, y la percepción/acción, que correspondía al verdadero comportamiento que se esperaba de Yemen como un miembro de la Sociedad de Estados. Consecuencia inmediata: la deportación de miles de trabajadores yemenís en varias de las monarquías del Golfo y el corte sustancial de ayuda externa (Burke, 2012).

En el mediano plazo este suceso generó un aislamiento por parte de los demás miembros de la Sociedad de Estados a lo largo de la década de los noventa (Azis, 1994). Desde la perspectiva de la élite estatal del norte, este hecho generó puntos a favor y en contra. Ocasionó perjuicios que se vieron reflejados en el deterioro de la economía nacional y del orden público; el aislamiento permitió a las elites estatales, especialmente la del norte, poder actuar de manera autónoma sin afrontar los costos de transgredir la normatividad internacional respecto a derechos humanos, punto fundamental para el desarrollo de la guerra civil, y dirigir en su beneficio la transición democrática.

A lo largo de los años 1990-1994, la élite estatal del norte reprodujo patrones autoritarios de RAY en el nuevo proyecto estatal como la concentración de poder en torno a la figura ejecutiva y el uso de la institucionalidad para dar mayor alcance a la red de patronazgo (Parodi, Rexford y Van Wie, 1994). Se gestó una alianza con el Partido Islah (organización paraguas de grupos islámicos); se configuró un cuadro de relaciones de conflicto intraélite en el cual de un lado se encontraban el CGP (Congreso General del Pueblo) e Islah, y del otro estaba el PSY (Partido Socialista Yemení).

Ya para 1993 se establecieron las condiciones adecuadas para que se presentara un conflicto armado (deterioro del orden público, incapacidad de las élites de llegar a un acuerdo y el aislamiento internacional) (Gasim y Patterson, 2013), el cual estalló cuando el PSY, en cabeza de 
Ali al-Baydh, tomó la decisión de revertir el proceso de unificación tras el triunfo electoral del CGP e Islah en 1993 (Nortlen, Grotz y Hartman, 2001).

El aislamiento de Yemen se manifestó en la ausencia de una reacción externa directa. Arabia Saudí, uno de los países con un antecedente histórico de intervención en Yemen, siguió siendo parte activa, especialmente a través de la Oficina de Asuntos Yemení (Hill y Nonneman, 2011). A nivel regional, se propuso una intervención directa si la Liga Árabe y el Gobierno de Yemen lo aprobaban, iniciativa que fracasó (Whitaker, 1994). Al interior de Naciones Unidas se emitieron resoluciones como la 924 y 931 en la cuales se pidió la finalización del conflicto armado, resaltando las implicaciones para la seguridad regional. Ninguna acción importante fue tomada.

El aislamiento alejó a Yemen durante este periodo de la noción de "constructor de Estado externo" y los beneficios de una ayuda internacional significativa le permitieron a la élite del norte involucrarse en el conflicto ignorando los constreñimientos generados por los derechos humanos (Carapico y Rone, 1994). Esta campaña finalizó cuando las tropas de Saleh lograron sitiar la ciudad de Adén, fortín político del PSY, expulsando, encarcelando y asesinando a la mayoría de socialistas.

A pesar de que durante los noventa hubo un incremento sustancial de misiones humanitarias (Davidson, 2012), no se tomó ninguna medida significativa frente a la precaria situación de la población yemení, lo cual puede ser en buena parte entendido por los efectos de las recientes intervenciones en Somalia, El Salvador, Uganda y Camboya, algunas de los cuales hicieron parte de los fracasos más significativos que han tenido las misiones de mantenimiento de paz.

\section{Fortalecimiento del Estado}

Tras el fin de la guerra civil de 1994, la coalición del norte obtuvo la victoria. Esto no solo significó el triunfo, sino que dio lugar a la consolidación del proceso de unificación a través de medios violentos, una anexión que tendría efectos negativos en el mediano plazo. Hasta el 
año 1994 el proceso de construcción de Estado estuvo enfocado en la pacificación de la élite estatal, es decir, la resolución del conflicto intraélite y la neutralización de fuerzas políticas contrarias al Estado con capacidad política y militar (Fattah, 2011). La otra dimensión en la que se concentró la elite estatal del norte fue el mantenimiento de las fronteras territoriales del Estado que se vio amenazado durante la guerra civil.

El periodo posterior a la guerra civil se caracterizó por el avance en términos de estatalidad y el fortalecimiento de la élite estatal en torno al partido de Gobierno CGP. La etapa de transición fue un suceso significativo en la región y fue tomada como modelo en la zona por Occidente; sin embargo, los importantes avances en derechos y libertades individuales se vieron derribados en el mismo momento en que el GCP comienza a apoderarse de toda la estructura estatal (Carapico, 1993).

Superada la amenaza política de los socialistas, se establece un equilibrio de poder entre las principales fuerzas en cabeza de tres líderes: A. Saleh, cabeza del gobierno del CGP y figura central de la red de patronazgo; el general M. Ali Mohsen, encargado del sur del país como comandante de la Región Oriental hasta 1999 (Saeed, 2012); y el jeque Abdullah al-Ahamar, principal líder de la confederación de tribus del norte Hashid y cabeza del partido Islah (Hill, Salisbury y Kinninmont, 2013). Catalogar los siete años que siguieron a la guerra civil como relativamente estables no excluye el hecho de que las relaciones entre las élites y la población seguían siendo conflictivas.

Durante estos años la élite gobernante del CGP pudo concentrar sus esfuerzos en la construcción de Estado, aunque con ciertas características particulares que fueron identificadas, como el uso de la red de patronazgo como estrategia para la pacificación interna. La distribución de recursos y castigos a través de esta red se convirtió en la herramienta del Gobierno para lograr una pacificación ante su incapacidad de garantizar el monopolio de la fuerza o de garantizar su presencia a través de canales institucionales. Esta estrategia era muy inestable y contribuía al establecimiento de un ambiente 
altamente competitivo por los escasos recursos que proveía la red de patronazgo (Egel, 2011).

A nivel de instituciones, la élite estatal hizo uso de estas con fines de avanzar en el proceso de democratización ${ }^{6}$ como una técnica infraestructural ${ }^{7}$ para incrementar el poder autónomo del Estado frente a la población y a los grupos importantes en su interior. En la búsqueda de conciliar la construcción de Estado con el proceso de inserción, la élite estatal decide emprender un proceso de transición democrática que en buena medida tuvo resultados positivos para la sociedad durante el periodo anterior a la guerra civil (Carapico, 1993). El modelo multipartidista, convenido por la élite del norte y del sur, cambió de dirección una vez finalizado el conflicto para ser un conjunto de reformas institucionales y políticas públicas que fueron usadas para incrementar el poder autónomo de la élite estatal gobernante.

Si bien el ambiente internacional no solo permitía, sino que fomentaba, transformaciones hacia Estados más liberales en términos políticos y económicos, también existían unas condiciones que posibilitaban a las élites estatales del Tercer Mundo acceder a un cierto nivel de improvisación a pesar de los constreñimientos que presentaba. Esto se hace evidente en el tema de la democratización, ya que no existe un consenso respecto a un concepto legal de democracia en el derecho internacional, lo que permite un mayor margen de maniobra a élites estatales para la manipulación de procesos de democratización sin ser sujeto de sanciones por parte de la comunidad de Estados (Saul, 2012). La vaguedad que rodea el concepto de la democracia hace más plausible la tesis según la cual, en las primeras etapas de los procesos de democratización, los resultados no sean democráticos (Tilly, 2006).

\footnotetext{
6 En el marco de la investigación se entendió la democratización como aquel conjunto de políticas públicas que buscan alcanzar el ideal de la democracia o lo que Tilly (2005) identifica como la garantía de consulta protegida.

7 Es la capacidad del Estado para penetrar la población y garantizar la implementación de decisiones (Mann, 2006).
} 
En términos económicos, la promoción de Estados liberales también permite ver el nivel de improvisación que tiene la élite estatal a pesar de las condiciones externas. Aunque a lo largo de los noventa la economía mostró avances a nivel macroeconómico con un crecimiento promedio de 5,5 \% (United Nations Department for Social and Economic Affairs, 2011), la concentración de la riqueza y el incremento de la desigualdad han sido característicos a nivel interno. A pesar de las reformas estructurales promovidas por el Banco Mundial y el Fondo Monetario Internacional en la mitad de la década de los noventa, la élite estatal tendió a hacer lo menos posible frente a la presiones originadas por la condicionalidad de la ayuda externa a la vez que mantenía el flujo de recursos (Colton, 2010).

Desde algunas perspectivas críticas como la de Escuela de la Dependencia latinoamericana, el fortalecimiento de las élites estatales se explica a través de la "tesis de la complicidad": élites estatales en el Tercer Mundo representan el interés de otros países externos a cambio de ciertos beneficios políticos de clase, étnicos, entre otros (Escobar, 2007; Galtung, Hager, Spraos, Massad y Urquidi, 1983; Jaguaribe, 1979 y 1988; Wallerstein, 2006). Sin descartar esta tesis, también es necesario identificar los momentos de autonomía de las élites estatales. En el caso de Yemen, se ve que ante la abstracción de conceptos normativos de la Sociedad de Estados y la incapacidad de control total de la asistencia condicionada, la élite yemení contó con un importante grado de autonomía que se vio acrecentado por el periodo de aislamiento relativo que atravesó el país.

\section{La lucha contra el terror: paradigma del Estado fuerte}

El siglo XXI inicia con una nueva premisa que refleja, y fortalece, el juicio respecto al incremento del componente social del sistema internacional de Estados: el Tercer Mundo, su estabilidad, es una de las piedras angulares de la seguridad global, directamente para las potencias y en general para el sistema (razón de sistema ${ }^{8}$ ). Esto

\footnotetext{
8 A diferencia de la razón de Estado, la razón de sistema comprende aquellos intereses que se desprenden no solo del mantenimiento de las unidades sino del ambiente en el cual se desenvuelven (Buzan, 2014).
} 
puede sintetizarse en la ampliación del sentimiento de inseguridad y su alcance a aquellos actores estatales y no-estatales que perciben en las debilidades de un determinado Estado vulnerabilidades o amenazas a su propia supervivencia. El interés que engloba la dimensión externa del predicamento de seguridad es la predilección de los actores estatales del sistema actual como el más adecuado, y de esto se desprende una preocupación en relación a su mantenimiento.

Aludiendo a este interés, Yemen implementó una estrategia de internacionalización de amenazas internas usada por varias élites del Tercer Mundo, lo que le permitió terminar con el relativo aislamiento que experimentó en los noventa. Tras el secuestro de turistas en Abyan (1998), el ataque al buque USS Cole (2000) y el ataque al buque carguero Limburg (2002), Yemen termina de incorporarse a la órbita de intereses geoestratégicos de Occidente (Carapico, 2006). A la relevancia para el mercado del petróleo, se adicionaba la preponderancia de ser un "santuario" para actividades ilegales.

Bajo la nueva lógica del "Estado fuerte", aquellas unidades que no desempeñaran adecuadamente sus funciones de control, regulación y centralización eran vistas como amenazas al orden y a la seguridad internacional, plataformas a partir de las cuales podían ser perpetuados ataques directos a las potencias de Occidente (Mantzikos, 2011). Antes de declararse la guerra contra el terrorismo, Saleh manifestó su compromiso con este en el año 2000 (Peterson, 2000), compromiso que se mantuvo en entredicho dada la ambigüedad de su acción frente a diversos grupos terroristas.

Gracias a este cambio en el ambiente internacional y al control casi total que logró el CGP frente al Estado a partir del año 2001, se privilegiaron y se promovieron estrategias de construcción de Estado dirigidas al fortalecimiento de la dimensión coercitiva del Estado. La ayuda que recibió Yemen favoreció el fortalecimiento de organismos de seguridad del Estado y la creación de algunos nuevos como la Oficina de Seguridad Nacional creada en 2002 y la Guardia Costera, en 2003. La ayuda internacional, que a partir del año 2000 se militarizó, no solo permitió el aumento de capacidades de control sino 
que permitió que todo el aparato militar de las Fuerzas Armadas se mantuviera en funcionamiento (Al-Zwaini, 2012).

A mediados de 2005 se consideró que Yemen no constituía una amenaza urgente a la seguridad. Las presiones provenientes de la Sociedad de Estados volvieron a incrementarse en torno a temas como derechos humanos y democracia. El Gobierno yemení presentó en la Casa Blanca un plan de reformas enfocadas al desarrollo y un plan de cooperación en seguridad (Embassy of Yemen, 2005). Durante esta reunión el entonces presidente estadounidense G. W. Bush hizo referencia a un giro de la asistencia enfocada en la democracia y en reformas estructurales (Jhonsen, 2012).

En 2006, tras el escape de varios miembros de al-Qaeda de una prisión en Sana'a (Yaif, 2006), la seguridad vuelve a tomar relevancia (Yaif, 2006). Esta vez se nota una mayor actividad de la élite yemení para mostrar diversas vulnerabilidades a la seguridad interna como amenazas a la seguridad global; "internacionalización del conflicto interno" sería el concepto que usaría A. Tickner (2007) para referirse a este fenómeno en el caso de Colombia. ¿Cuáles eran aquellas amenazas? Si bien en términos amplios se podría identificar más de un factor que puede ser considerado una amenaza a la seguridad, el Gobierno logró crear un consenso frente a otros miembros y a la opinión pública: las vulnerabilidades a la seguridad más importantes para el caso de Yemen eran el Movimiento del Sur, la rebelión Houthi y al-Qaeda en la península arábiga (AQPA).

Frente a estas vulnerabilidades, existía una clara diferenciación en el cálculo de prioridades que hacían el Gobierno yemení y otros Estados. Si bien para el Gobierno AQPA era una preocupación, los hutíes y el Movimiento del Sur representaban una mayor urgencia. Arabia Saudí, debido a las implicaciones de la rebelión Houthi en la zona fronteriza, fue el único país que compartía las preocupaciones del Gobierno yemení más allá de la amenaza terrorista que planteaba AQPA (Khashoggi, 2014). 
Eran también estos grupos los que hacían de Yemen un territorio sin Gobierno, con zonas que desde el enfoque del Estado fuerte se presentaban como vulnerabilidades al sistema (Mols, 2011). Aunque es evidente el enfoque en seguridad que tuvieron las relaciones con Yemen con el resto de miembros de la Sociedad de Estados y otros tipos de organizaciones, el trasfondo se puede encontrar en el mismo proceso de construcción de Estado que emprendió la élite estatal tras la finalización de la guerra civil de 1994. Es decir que, a nivel interno, se presentaron las condiciones adecuadas para que el Estado pudiera implementar las estrategias que se desprendían del enfoque predominante en cuanto a construcción de Estado a partir del año 2000.

El argumento del "caos controlado" o "manufacturado" ha sido una de las tesis con las que se ha explicado la situación interna yemení (Sharp, 2012). Estas sostienen que el Gobierno, de manera intencional, promueve la inestabilidad política interna con el fin de obtener recursos externos. Frente a esta tesis es más adecuado pensar en las distintas situaciones de inestabilidad y las múltiples amenazas a la seguridad al Estado como consecuencias del proceso de centralización estatal más que como situaciones generadas de manera deliberada por la élite estatal. Dicha situaciones no podrían ser concebidas como deseables en su totalidad ya que en ellas reside el constante sentimiento de inseguridad que pretenden superar las élites del Tercer Mundo.

Por otro lado, la internacionalización de vulnerabilidades no tendría sentido sin una matriz social que lo permita. El paradigma del Estado fuerte simplemente se muestra como el concepto que engloba preocupaciones de orden social del sistema internacional de Estados. Refleja la necesidad de estabilizar las unidades estatales como partes fundamentales para el mantenimiento del sistema, de fortalecer su capacidad de centralización de la vida social y de controlar fuerzas sociales en su interior. Dado el carácter desigual y jerarquizado de la Sociedad de Estados (Delbruck, 2001; Lake, 2004; Milanovic, 2006 y Lees, 2012), las acciones que se llevan a cabo en favor de su mantenimiento y de las unidades que la conforman están influenciadas por la dependencia tanto en términos de acciones colectivas como de implementación individual. 
Este enfoque que se da en las relaciones interestatales, en especial entre los miembros fuertes y débiles, se manifiesta a través de la promoción de la construcción de Estado como una actividad intencional y enfocada en sus tareas primarias (pacificación y extracción de recursos). Estas responden a una elucidación (visión) de lo que debe ser la Sociedad de Estados y por ende determina las acciones a llevarse a cabo mas no sus resultados.

Bajo esta perspectiva, la matriz social en la cual se articulan las relaciones interestatales es la que hace que aquellos Estados que se ubiquen como no insertos tengan una capacidad reducida de alterar prácticas o valores de manera intencional. Esto, sumado a que se encuentran en estadios tempranos de construcción de Estado los convierte en objeto de dos circunstancias: 1) Las implicaciones estructurales de la anarquía internacional se reduce para los miembros más débiles de la Sociedad de Estados. La desigualdad de capacidades materiales es tan exacerbada que estas no representan una vulnerabilidad para la seguridad de las principales potencias o para el statu quo, con excepción de situaciones especiales como la posesión de armas nucleares. 2) Los países más débiles se ven más expuestos a los constreñimientos que tienen su origen en los valores y normas que fundamentan la Sociedad de Estados.

La promoción de la construcción de Estado tiene efectos en las estructuras sociales internas de los Estados con la finalidad de acumular recursos y asegurar la supervivencia. De igual manera se generan subjetivaciones de valores que provienen de Occidente, lo que resulta en estrategias particulares de construcción de Estado y formas específicas en las que la población lleva a cabo la resistencia popular.

De esto se desprende una crítica a la explicación tradicional del comportamiento estatal como actor racional y el concepto de interés como resultado de la anarquía internacional. Aunque el paradigma del "Estado fuerte" corresponde a una visión estadocéntrica, en ella misma palidece el equilibrio de poder como guía del comportamiento y del dilema de seguridad. Este paradigma muestra cómo el interés es 
precisamente el fortalecimiento de otros Estados bajo ciertos criterios sociales y condiciones estructurales.

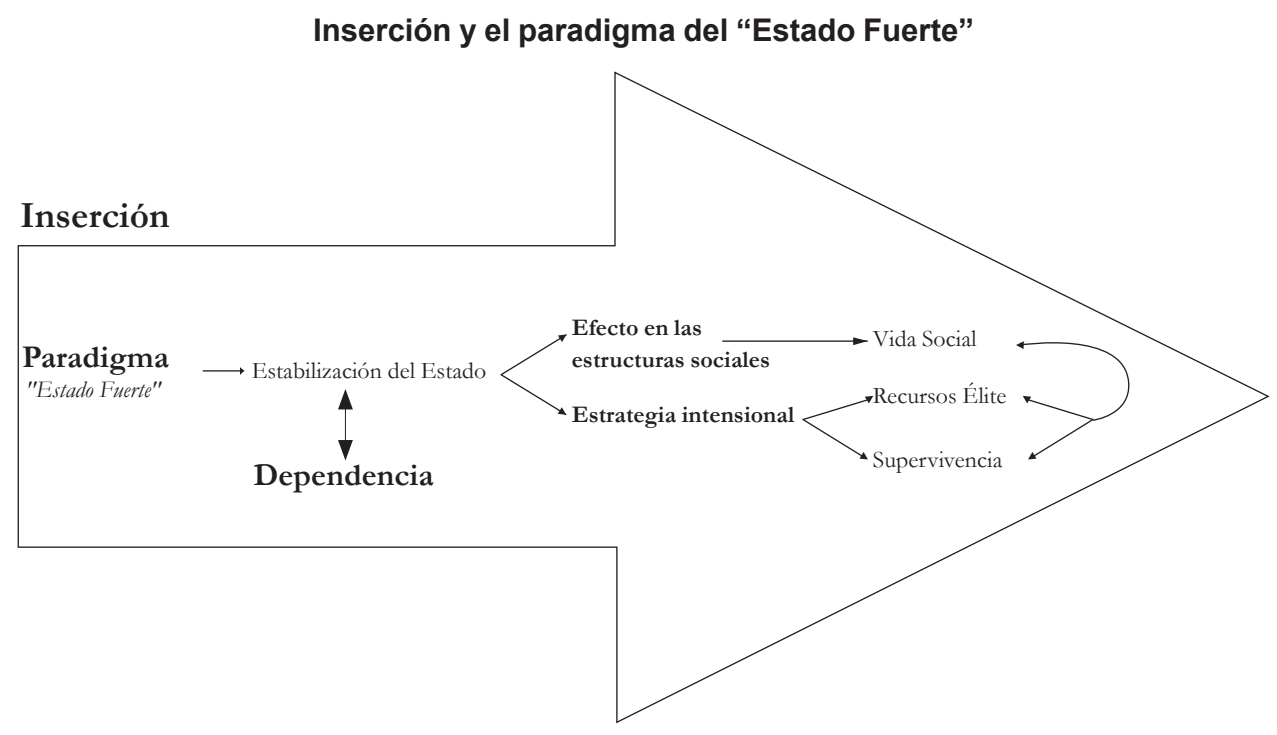

Fuente: Elaboración propia.

En el caso de Yemen, la construcción de Estado, los constantes esfuerzos por lograr un nivel de inserción y la búsqueda por superar el sentimiento de inseguridad por parte de la élite estatal terminarían por concretar las condiciones adecuadas a partir de las cuales se daría una crisis política en el marco de un suceso regional: las revueltas árabes.

\section{Revueltas árabes en Yemen y el oredicamento de seguridad}

A lo largo de los primeros veinte años de la construcción de Estado yemení el CGP logró un monopolio del Estado tal que se lo asociaba con el mismo Estado (Longley, 2007). La consecuencia inmediata fue avanzar en el proceso de centralización de la vida social de la población. En las elecciones de 2006 se termina de consolidar el dominio del CGP a nivel parlamentario y local a pesar de los esfuerzos de la oposición por crear una coalición que permitiera hacer frente al partido 
de gobierno (Al-Sakkaf, 2013). Junto al proceso de centralización, el uso de la red de patronazgo y la democratización como estrategias de construcción de Estado, se consolidó en el país un ambiente político altamente competitivo y un importante sector de la población marginada. En este ambiente interno inician las revueltas árabes.

\section{La crisis política de 2011: las revueltas árabes}

Las revueltas empezaron en Yemen en el mes de febrero de 2011 cuando grupos de estudiantes y otros sectores de las principales ciudades protestan en favor de la finalización del régimen de Ali A. Sahle. A lo largo de meses las manifestaciones se intensificaron hasta alcanzar una escala nacional y con ello incrementaron las medidas represivas del Estado (Rodríguez, 2012). La razón por la cual estas tuvieron un impacto para el predicamento de seguridad yemení es el haber dado lugar a una crisis política en la que el periodo presidencial de Ali A. Saleh finalizaría; se afectó una de la dimensiones de seguridad contempladas desde la perspectiva subalterna: la gubernamental (Ayoob, 1995).

Con el fin de articular el concepto de crisis política con la perspectiva subalterna, esta fue entendida como el momento crucial en el que se ve amenazada la supervivencia del Estado (territorio, Gobierno y/o instituciones). Es un periodo de tiempo relativamente corto, caracterizado por la priorización de temas concernientes a la seguridad del Estado y el orden político (Widmajer y Seabrooke, 2007). La culminación de la crisis es la restitución del statu quo, el control de la crisis o la materialización de una amenaza con el potencial de alterar el territorio, las instituciones y/o el Gobierno. Desde la perspectiva de la construcción de Estado, la secesión (Ayoob, 1995) y la revolución (Sckocpol, 1979) se presentan como las mayores amenazas a las que se puede enfrentar la élite estatal. La crisis no necesariamente está vinculada con el cambio (Rosenau, 1990).

Tras salir de una especie de anonimato en el cual se encontró sumergido el país en los noventa (O'neill, 2009), comienzan a desarrollarse las condiciones que lo convertirían en una amenaza directa para ciertos Estados y para el orden mundial en general. En 2010, 
Yemen es catalogado por la administración estadounidense como un país de "alto riesgo" y los enviados gubernamentales demostraron en más de una ocasión preocupación por la falta de confianza que tenían frente al Gobierno yemení en cuanto a su compromiso con el mantenimiento del orden (Jerome, 2010); el flujo de recursos se mantuvo durante este periodo e incluso después de la finalización del gobierno de Ali A. Saleh.

La imagen de Yemen en el momento en que inician las revueltas no era la mejor. Existían ciertas dudas respecto al compromiso del Gobierno frente al sistema y las condiciones internas del país hacían dudar de la capacidad de este de lograr responder a las exigencias de ser un miembro de la Sociedad de Estados. Yemen no era visto bajo la perspectiva inmovilista con la que se han caracterizado los demás países del Golfo. Esto, ciertamente, conlleva a dos planteamientos: ¿cuál es la capacidad del sistema de Estados de regular comportamientos y procesos? Y, ¿por qué la constante ayuda por parte de ciertas potencias a pesar de todas las dudas que despertaba el Gobierno yemení?

Estas preguntas pueden ser abordadas a partir de la noción del efecto externo del predicamento de seguridad (Ayoob, 1995, pp. 139-164) en donde por un lado el componente sistémico ofrece un panorama altamente interactivo y complejo, y por otro nos encontramos con un componente social en el cual la interdependencia de las unidades y su complejidad encuentran manifestaciones particulares. En síntesis, lo que explican estas dos dimensiones es la inaplicabilidad del "todo vale" para hacer frente a la crisis yemení, tanto por parte del Gobierno Nacional como de otros actores interesados; no se trata solo de la distribución del poder material de los actores sino de las normas y reglas que regulan el comportamiento de cuya interpretación se desprende una trayectoria (Kupchan, 2014).

Las revueltas árabes de 2011, la crisis que se produjo en Yemen y la finalización del periodo presidencial de Ali A. Saleh, conllevan casi que de manera directa al planteamiento del Estado. Es parte de un proceso de acumulación de injusticias y procesos organizativos (Currea, 2012) del cual surge un proyecto de resistencia popular que tenía la 
intención de cambiar la forma de hacer política en Medio Oriente y la estructura internacional que promovía el Estado árabe (Ismail, S. e Ismail, T., 2013). Las presiones tanto internas como externas que recibió durante este periodo el Gobierno yemení giraban en torno al tema del Estado por parte de la población interna, en cuanto a la incapacidad de garantizar ciertas condiciones sociales y políticas; y por parte de actores externos en lo que se refiere a la incapacidad de regulación interna de la población, a la pacificación, y a la restricción de los efectos negativos al interior de sus fronteras. En ambos casos se hace referencia a lo que pueden considerarse niveles adecuados de estatalidad (Marin, 2012).

En estos dos tipos de demandas, aquellas que derivan de la Sociedad de Estados y de la población interna yemení ${ }^{9}$, se encuentra uno de los mayores obstáculos a los que se tuvo que enfrentar la élite y que en general se presenta como un problemática para la mayoría de los Estados: el conflicto que se genera entre unidad y diversidad (Walker, 2012); la conflictividad que tiene lugar por la existencia simultánea de centralización y descentralización de la vida social de la población de un Estado. A nivel de procesos promovidos por la Sociedad de Estados, esta contradicción se manifiesta en la marcha hacia la democratización (descentralización del poder e incremento de la consulta protegida) y en la construcción de Estado (centralización del poder político, pacificación y extracción de recursos).

Desde el inicio de su existencia como Estado, la República de Yemen se enfrentó a un tipo de problemática distintiva de los Estados del Tercer Mundo desde el siglo XX: las exigencias que genera el sistema por el incremento de niveles adecuados de estatalidad en medio de los constreñimientos generados por los procesos de centralización y la difusión de los derechos humanos, todo esto en el marco de la ideología liberal que ha caracterizado el periodo de pos Guerra Fría. Esto quiere decir que el "todo vale" tampoco era una opción para la élite estatal yemení.

\footnotetext{
9 Estas no se presentan necesariamente de manera contradictoria. Es decir, las demandas internas y externas también pueden comulgar bajo ciertas condiciones.
} 
Aunque el incremento de los niveles de estatalidad es una meta deseable por los miembros de la Sociedad de Estados para el mantenimiento del orden político interno (Agnew, 2005; Kim, 2009; Miller, 2013; Skocpol, 1979; Scokpol, 1985 y Tilly, 2006), resalta la importancia que tiene el reconocimiento por parte de los demás miembros y el consentimiento que el miembro en cuestión muestre frente al orden prevaleciente. La ausencia de reconocimiento del Gobierno yemení por parte de sus principales aliados (Estados Unidos y Arabia Saudi) determinaría la finalización de la presidencia de A. Saleh y el inicio de un periodo de transición que habría sido propuesto por el Consejo de Cooperación del Golfo (CCG).

La ausencia de reconocimiento también se presenta a nivel interno pero en otro sentido en la medida en que corresponde más al proceso de una construcción de Estado caracterizada por la implementación del patronazgo como estrategia para alcanzar la pacificación y la democratización como herramienta infraestructural del Estado. La configuración de la crisis política de 2011 se da cuando la población no reconoce al Gobierno no solo como la autoridad política central sino como el eje de la red de patronazgo. En esta medida, y pasados ya algunos años de este suceso, el resultado de esta crisis no podría ser entendido en términos de cambios profundos en el sistema político yemení. Lo que sucedió fue una reorganización de fuerzas mientras que las estructuras e instituciones internas se mantuvieron casi intactas.

\section{Predicamento de seguridad yemení y el orden mundial}

Las revueltas árabes en Yemen brindan un buen ejemplo para la comprensión de la resistencia popular, del que las revueltas de 2011 como tal cuales fueron un periodo relativamente corto de clímax. La resistencia popular, la mayor parte del tiempo, toma forma a partir de actos que no son tan disruptivos pero que, dada su persistencia, logran influir de manera determinante en el proceso de construcción de Estado. En la medida en que se incrementan los esfuerzos de la élite por centralizar la vida de la población y más son los aspectos en los que se inmiscuye el Estado, son más las formas en que se manifiesta la resistencia popular; existen fuerzas externas que también son fundamentales en la definición de las múltiples manifestaciones de la resistencia. 
La noción de desarrollo de las capacidades analíticas de los ciudadanos estudiada por Rosenau (1990) es adecuada para la comprensión de la resistencia popular en Yemen. Dicho desarrollo se muestra como un proceso de aprendizaje y adaptación. A diferencia de lo que plantea Rosenau, este proceso por el que pasan las personas no solo responde a la interacción de los individuos con las transformaciones espaciales que plantea la globalización y el flujo a través de las fronteras (Scholte, J. 2000); tampoco se reduce a la difusión de ideas democráticas y de los derechos humanos. Responde a la forma en que las poblaciones experimentan los procesos de gran escala y las políticas que se desprenden de la construcción de Estado.

La población yemení no solo experimentó un periodo en el cual se difuminarían valores democráticos y ciertas tendencias vinculadas a la globalización (Carapico, 2006), también respondió a la construcción de Estado y a sus características particulares. Los constantes avances en cuanto a centralización del poder político a partir de la finalización de la guerra civil de 1994 dieron lugar a formas de organización de la resistencia que lograron encontrar en el presidente A. Saleh un nodo de articulación que permitió que las revueltas tuvieran la dimensión que alcanzaron (López, 2012; Rodríguez, 2012).

Otro factor decisivo fue el que este suceso se haya presentado en el marco de una crisis política de escala regional. Esto creó las condiciones adecuadas para el final de varios regímenes en Medio Oriente. Para el caso de Yemen, disminuyó las probabilidades de una intervención directa por parte de otros Estados de manera individual o a través de una acción conjunta debido a la priorización que se dio a los diversos países involucrados.

\section{Construcción de Estado: ¿Solución al predicamento?}

Durante las últimas décadas se ha notado un incremento por parte de los Estados en el desempeño de tareas que buscan revertir o disminuir al máximo los efectos perjudiciales de las fuerzas centrífugas que operan en el sistema. A causa de ciertas tendencias descentralizadoras y de la interdependencia, el predicamento del Tercer Mundo se ha convertido en una problemática a la cual se ha hecho frente a 
través de acciones dirigidas directamente a la inserción y a la construcción de Estado.

A lo largo de los últimos quince años se puede encontrar una serie de acciones por parte de las potencias que buscan responder a hechos que han determinado el periodo actual: la turbulencia del sistema, la consecuencias de la bipolaridad y la globalización desigual (Barbe, 2004). Detrás de la presencia de las potencias en el Medio Oriente se puede encontrar un significante, un valor político, en torno al Estado y según el cual se articulan las relaciones de las potencias con Yemen: la construcción de Estado. Precisamente durante estos últimos años se ha fortalecido la noción de que los Estados fracasados o vulnerables se constituyen en una especie de vacíos en los cuales se gestan constantes amenazas al orden y a la seguridad mundial (Duffield, 2008; Mantzikos, 2011). De aquí las nociones como "anarquía", "caldo de cultivo" o "santuario" usadas para hacer referencia a estas zonas geográficas en las cuales no existe un Gobierno estatal de facto.

Al volver a la pregunta de investigación según la cual se busca indagar acerca del papel de la construcción de Estado y la inserción en la crisis de 2011, se llega a la conclusión de que sí existió un rol determinante en la medida en que el predicamento de seguridad influyó en el comportamiento de la élite estatal yemení cuyas acciones contribuyeron a consolidar las condiciones y a los actores que hicieron posible la finalización del régimen. Sin embargo, más allá de los temas de seguridad, se ha visto cómo los diversos intentos por la superación del sentimiento de inseguridad obedece al componente sociedad, a los principios y normas que se integran en la regulación de los actores.

El incremento del componente sociedad no se vio como contradictorio con conceptos como dependencia, jerarquización, desigualdad o dominación. Son estos los que dan sentido precisamente a la Sociedad de Estados y a las manifestaciones particulares que se desprenden de los valores políticos y sociales que articulan sus instituciones. 


\section{Conclusiones}

A través del caso de Yemen durante el periodo 1990-2011 se ha permitido observar una de las formas en que se ha caracterizado el desarrollo del sistema internacional durante estos años. Si bien es cierto que los sucesos particulares que han sucedido en Yemen no son suficientes para el establecimiento de un cuerpo teórico lo suficientemente amplio y exacto para poder determinar el comportamiento estatal en el Tercer Mundo en su totalidad, sí ha permitido, a través de la revisión del predicamento de seguridad, analizar aquellas fuerzas que han dado lugar a un incremento en el componente sociedad del Sistema de Estados.

El realismo subalterno no pretende explicar la política mundial en su totalidad (Ayoob, 1989; 1995) y en cierta medida, dado su fuerte influencia del realismo, es reduccionista en la explicación que puede brindar de ciertos sucesos; el Estadocentrismo y la concepción de seguridad son sus más importantes limitantes. A pesar de esto brinda luces para realizar un trabajo crítico y analítico frente a los tiempos actuales.

A diferencia de otros paradigmas, rescata la importancia que tienen los procesos de construcción de Estado en la actualidad, en especial para los miembros más débiles de la Sociedad de Estados. A su vez, gracias a la consideración de la inserción en el sistema internacional, se puede contextualizar cómo la construcción de Estado no se desarrolla en el vacío y por el contrario responde a ciertos valores instituyentes en torno a los cuales se ha articulado la Sociedad de Estados durante su última etapa (periodo pos Guerra Fría). Muchos de los aportes que se han realizado respecto al surgimiento de una política mundial posmoderna (Cooper, 2000) o posnacional (Parker, 2004) han sido fundamentales para el desarrollo del campo, pero también es importante considerar las continuidades respecto a los periodos precedentes, algo que trata de hacer el realismo subalterno.

Algunas que cabe resaltar, y que fueron trabajadas a lo largo de la investigación, son la relevancia, a pesar de las trasformaciones en el ambiente y los actores, del papel del Estado para el funcionamiento 
del sistema (Rodrik, 2012); el papel de la seguridad y su relación con el poder y los recursos militares; y la persistencia de ciertas consecuencias de la anarquía internacional. Estos elementos son asociados con lo que se considera parte de los principios del sistema internacional moderno (Tomassini, 1991, p. 15).

\section{Predicamento de seguridad en el siglo XXI}

Como se resaltó al principio de este escrito, la principal característica que ha dado forma al predicamento de seguridad durante el periodo de pos Guerra Fría fue el incremento del componente sociedad. Esto se explica por el predominio de principios instituyentes que regulan el comportamiento de los Estados en torno a la ideología liberal. Lo que conlleva a la diferenciación de dos elementos en el marco de la perspectiva subalterna, es decir, entre inserción en el componente sistema y en el componente sociedad del Sistema de Estados. El sistema hace referencia de manera específica a la intensidad de las interacciones (Bull, 2005; Rosenau, 1991; Wallerstein, 2006; Waltz,), o sea, el incremento o disminución de las interacciones es lo que da sentido al componente sistémico. Estas pueden darse sin requerir algún consenso u homogeneidad de las partes; cooperación, conflicto, heterogeneidad, turbulencia, entre otras características son aquellas que hacen este componente.

De otro lado, lo que podría ser considerado una inserción a la sociedad de Estados corresponde a un proceso social vinculante a través del cual un actor se vincula a una forma de organización social en calidad de miembro. Este denota conocimiento, voluntad e intencionalidad por parte del Estado (élite estatal) que está atravesando el proceso (Ayoob, 1989; Bull, 2005; Dunne, 1998; Brems, 2000; Buzan, 2014; Buzan y Peláez, 2009). Este se caracteriza por una cohesión que se hace perceptible en las manifestaciones del comportamiento y en los principios instituyentes que rigen los procesos históricos. Un ejemplo de esto es cómo, a pesar de la heterogeneidad de los actores, la soberanía sigue siendo un principio rector en las relaciones interestatales e influye en el comportamiento de actores no estatales. 
Este consenso tiene una de sus principales implicaciones en la predilección de una forma de organización de la política internacional, de la cual surge un interés en el mantenimiento del sistema que implica la protección del todo (razón de sistema) y sobre la cual la versión anárquica del sistema puede ser sujeto de ciertas críticas como aquellas que se desprendieron en torno al análisis del paradigma del "Estado fuerte".

En cuanto a la diferenciación entre control y regulación, ciertos sucesos acaecidos a lo largo del periodo de pos Guerra Fría han contribuido a la consolidación de la política mundial como dominada por la anarquía estructural, fortaleciendo el predominio de los paradigmas tradicionales (Beitz, 1999). Una de las consecuencias es el incremento de la percepción acerca de la incapacidad de la sociedad de Estados para regular el comportamiento. Actores no estatales y procesos de descentralización de la vida social se presentan como los argumentos en favor de esta tesis. Constantemente, los actores pasan por encima de lo marcos normativos y jurídicos, en especial cuando se trata de momentos de tensión o de crisis. A este respecto es pertinente establecer qué es lo que diferencia el control de la regulación, estableciendo brevemente en qué consiste la capacidad de regulación del sistema interestatal.

La regulación hace referencia a la influencia que tienen ciertos criterios organizacionales (principios, normas, formas de entendimiento) sobre el comportamiento de los actores, influencia que no puede ser entendida en términos de un control absoluto. La autonomía es una potencialidad presente de manera constante en el actor (Castoriadis, 1979, pp. 172-190; Dussel, 2006, pp. 26-28; Escude, 2012, pp. 36-37), por lo cual el control, es decir la directriz de una autoridad sobre un actor para que se comporte de una forma específica, no se puede dar de manera total, mucho menos determinar sus efectos; el actor no solo cuenta con capacidad de resistencia sino de improvisación y creación. Para el caso de Yemen, se establecen unas circunstancias en las cuales la élite gobernante era inducida a comportarse de cierta manera, pero no podría hablarse de un control en términos restringidos. 
Las obligaciones que contraía el Estado yemení al aceptar llevar a cabo procesos estatales y democráticos para convertirse en parte activa del sistema capitalista limitaba las opciones que tenía, lo enfrentaba a regulaciones. Por otra parte, no podría decirse que fue controlado o instrumentalizado totalmente en la medida en que toda la ayuda y apoyo, financiero o político, que fueran condicionados no dio origen a acciones con efectos específicos.

Los actores no estatales al interior de la fronteras nacionales, de igual manera, no se ven controlados por la sociedad de Estados pero sí regulados en el sentido tratado anteriormente. Su comportamiento se ve influenciado por la existencia de un Estado yemení: saben en qué momento se cruza una frontera jurídica, cómo responden a las autoridades nacionales y externas, todo esto en medio de la consecución de sus objetivos. Son los efectos de la regulación los que, en parte revelan, el incremento del componente sociedad, el fortalecimiento de la sociedad de Estados y la proliferación del Estado. A lo largo y ancho de todo el planeta Tierra poblaciones e individuos se relacionan con Estados sea en términos de complicidad, de participación activa o de resistencia, y esta sería la regulación inmediata que la sociedad de Estados tiene.

Una de las tesis propuestas por Ayoob (1997) para explicar el comportamiento de los Estados del Tercer Mundo fue la esquizofrenia de las élites estatales. Desprendida de la teoría sobre regímenes de Krasner (1981), esta hace referencia a una doble actitud de las élites estatales en el Tercer Mundo: a nivel de acciones individuales se muestran a favor del mantenimiento del statu quo, mientras que en la acción colectiva muestran una actitud revisionista. Con el incremento del componente sociedad en el sistema, los sucesos que se desprenden de esta actitud colectiva han disminuido; el Tercer Mundo habría perdido el espacio político que tuvo durante la Guerra Fría (Buzan, 2003). El incremento del componente sociedad, en este sentido, se manifiesta en torno a los significantes a los cuales se ha dirigido la acción humana durante las últimas décadas; desde mediados del siglo XX se puede hablar de un mundo repleto de Estados, o de intentos de. Sin embargo, con el inicio del periodo de pos Guerra Fría se puede hablar de una homo- 
genización de significantes en el marco de una economía y de una política liberal. La esquizofrenia ha sido superada en buena medida.

La colonialidad, la geopolítica del conocimiento (Slater, 2008), los procesos de descolonización, son muchos de los procesos que ayudan a identificar las particularidades (heterogeneidad) entre los diversos actores estatales y las manifestaciones que tienen en las poblaciones. Reconocer esta heterogeneidad no entra en contradicción con la noción de totalidad (Quijano, 2007) que ofrece la sociedad de Estados y su capacidad de regulación.

El periodo de pos Guerra Fría, a pesar de los constantes sucesos que conducen a identificar la política internacional como carente de orden, basada en los principios de la anarquía estructural en su forma más primigenia, ha sido el momento en que el sistema internacional ha experimentado un mayor incremento en el componente "sociedad". Debido a esto las potencias y el Tercer Mundo se comportan como lo hacen, razón por la cual se rigen los procesos de vinculación al sistema. En el incremento de este componente se refuerzan la dependencia, la colonialidad y la desigualdad, es decir, el sentimiento de inseguridad.

\section{Referencias}

Aboott, C., Rogers, P. F. \& Slobada, J. (2006). Global Responses to Global Threats: Susteinable Security for the 21st Century. Oxford: Oxford Research Group. Recuperado de http://www.oxfordresearchgroup.org.uk/ sites/default/files/globalthreats.pdf

Agnew, J. (2005). Sovereignty Regimes: Territoriality and State Authority in Contemporary World Politics. Annals of the Association of American Geographers, 95 (2), 437-461.

Al Sakkaf, N. (2013). JMP. The Beginning of the End. Yemen Times. Recuperado de http://www.yementimes.com/en/1657/viewpoint/2093/ JMP-the-beginning-of-the-end.htm

Al-Zwaini, L. (2012). The Rule of Law in Yemen: Prospects and Challenges. Law Enforcement Hiill. Recuperado de http://www.hiil.org/ publication/country-quick-scan-yemen 
Amin, S. (2001). Imperialismo y globalización. Globalización. Recuperado de http:/ / rcci.net/globalizacion/2001/fg175.htm

Ayoob, M. (1989). The Third World in the System of States: Acute Schizophrenia or Growing Pains? International Studies Quarterly, 33 (1), 67-79.

Ayoob, M. (1995). The Third World Security Predicament. Londres: Lynne Rienner Publishers.

Ayoob, M. (1997). Redifining Security: A Subaltern Realist Perspective. En Krauser, K. y Williams, M. C. Critical Security Studies: Concepts and cases (pp. 121-146). Minneapolis: University of Minessota Press.

Azis, B. (1994). Yemen's Strife is a Symbol of Post-Soviet Turmoil. National Catholic Reporter, 30, (34), 11.

Barbe, E. (2004). Orden internacional: ¿Uno o varios? Neoimperialismo, caos y postmodernidad.I. Orden Internacional, aproximación teórico-conceptual. Cursos de Derecho Internacional y Relaciones Internacionales VitoriaGasteiz. Recuperado de http://www.ehu.eus/cursosderechointernacionalvitoria/ponencias/pdf/2004/2004_1.pdf

Beitz, C. (1999) Politicial Theory and International Relations. Nueva Jersey: Princeton University Press.

Bonnefoy, L., Hill, B. \& Ottaway, M. (2012). Salafis in Yemen: Caught in the Revolution? Carnige Endowment for International Peace. Recuperado de http://carnegieendowment.org/2012/01/24/salafis-in-yemencaught-in-revolution/91ze

Brems, T. (2000). International Society and International Solidarity: Recapturing the Solidarist Origins of The English School. International Relations in Europe: Concepts, School and Institutions, $28^{\text {th }}$ Joint Session of Workshop, pp. 14-19.

Brenner, N. (1999). Beyond State-Centrism? Space, Territoriality, and Geographical Scale in Globalization Studies. Theory and Society, (28), 39-78.

Bull, H. (2005). La sociedad anárquica: un estudio sobre el orden en la política mundial. Madrid: Catarata.

Burke, E. (2012). One Blood and one Destiny? Yemen Relations with the Gulf Cooperation Council. Kuwait Programme on Development, Governance and Globalisation in the Gulf States, 23. Londres: London School of Economics and Political Science. Recuperado de http:// www.lse.ac.uk/middleEastCentre/kuwait/documents/yemen-andthe-gcc.pdf 
Buzan, B. (2003). Regions and Powers: The Structure of International Security. Cambridge: Cambridge University Press.

Buzan, B. (2004). From International to World Society: English School Theory and the Social Structure of Globalization. Cambridge: Cambridge University Press. Buzan, B. (2014). An Introduction to the English School of International Relations. Cambridge: Polity.

Buzan, B. \& Peláez, M. (2009). International Society and The Middle East. English Theory School at the Regional Level. Hampshire: Palgrave Macmillan.

Carapico, S. (1993). Elections and Mass Politics in Yemen. Middle East Research Report 185, 25 (6), 2.

Carapico, S. (2006). No Quick Fix: Foreign Aid and State Perform in Yemen.

Birdsall, N., Milan, Vaishnav, M., y Ayres, R. L. Short of the Goal: U.S.

Policy and Poorly Performing States. Washington, D.C.: Center for Global Development, pp. 182-208.

Carapico, S. \& Rone, J. (1994). Yemen: Human Rights in Yemen During and After the 1994 War. Human Rights Watch/Middle East, 6 (1), 1.

Carr, E. (1946). The Twenty Years' Crisis 1919-1939: An Introduction to the Study of International Relations. Edinburgh: Macmillian \& Co. LTD.

Castoriadis, C. (1983). La institución imaginaria de la sociedad. Barcelona: Tusquets.

Colton, N.(2010). Yemen a Collapsed Economy. Middle East Journal, 64 (3), 410-426.

Cooper, R. (2000). The Post-Modern State and the World Order. Demos. Recuperado de http:/ / www.demos.co.uk/files/postmodernstate.pdf. Corbi, K. (2012). Small Arms Tracfficking in Yemen: A Threat to Regional Security and Stability. New Voices in Public Policy, 6 (1), 4.

Cox, R. (2014). Fuerzas sociales, Estados y órdenes mundiales: Más allá de la teoría de las relaciones internacionales. Relaciones Internacionales, 0 (24). Recuperado de http:/ / www.relacionesinternacionales.info/ojs/ article/view/501.html

Davidson, J. (2012). Humanitarian Intervention as Liberal Imperialism: A Force for Good? POLIS Journal. (7), 128-164. Recuperado de http:/ / www.polis.leeds.ac.uk/assets/files/students/student-journal/ug-summer-12/joanna-davidson.pdf

Delbruck, J. (2001). Structural Changes in the International System and its Legal Order: International Law in the Era of Globalization. Zeitschrift fur internationales und europaisches Recht, (11), 1-36. Recuperado de http:/ / 
www.ivr.uzh.ch/dam/jcr:00000000-6cd4-2fa7-0000-000056bb30f7/ Text_1_Delbrueck.pdf

Duffield, M. (2008). Los Estados frágiles y el retorno a la administración nativa. Relaciones Internacionales, (8). Recuperado de http://relacionesinternacionales.info/ojs/article/view/105/96.html

Dunne, T. (1998). Inventing International Society. A History of the English School, London, 6-11. Recuperado de: http://www.ssu.edu.tr/uploads/ Article-8_9R3ssc81.pdf

Dussel, E. (2006). 20 Tesis de Política. México D. F.: Siglo XXI editores.

Egel, D. (2011). Tribal Heterogeneity and Allocation of Development Resources: Evidence for Yemen. Topics in Middle Eastern and African Economies, 13. Recuperado de http://www.luc.edu/orgs/meea/volume13/PDFS/Egel.pdf

Embassy of Yemen. (2005). The Working Visit of H. E. Ali Abdullah Saleh. Yemeni-American Relations. Recuperado de http://yemenembassy. org/issues/ymusrelshp/index.htm

Escobar, A. (2007). La invención del Tercer Mundo: Construcción y desconstrucción del Desarrollo. Caracas: El Perro y la Rana.

Escudé, C. (2012). Principios del realismo periférico. Una teoría argentina y su vigencia ante el ascenso de China. Buenos Aires: Ediciones Lumiere.

Fattah, K. (2011). Yemen: A social Intifada in a Republic of Sheikhs. Middle East Policy, 18 (3), 79-85.

Galtung, J., Hager, W., Spraos, J., Massad, C. \& Urquidi V. (1983). Problemas económicos del Tercer Mundo. Buenos Aires: Belgrano. Recuperado de http:// repositorio.cepal.org/bitstream/handle/11362/8472/S3821P964_es.p $\mathrm{df} ;$ ssessionid $=$ C68B4C9AEB43E940BF72621210B303A7? sequence $=1$

Gandasegui, A. (2007) Crisis de hegemonía de Estados Unidos. Mexico D. F.: Siglo XXI.

Gasim, G. \& Patterson, D. (2013). Institutional Reforms in Yemen. Yemen Times. Recuperado de http://www.yementimes.com/en/1683/report/2462/Institutional-Reforms-in-Yemen.htm.

Grinin, L. (2013). State and Socio/Political Crisis in the Process of Modernization. Social Evolution \& History, 12 (2). Recuperado de http:// www.socionauki.ru/journal/files/seh/2013_2/035-076.pdf

Heibach, J. \& Ouaissa, R. (2015). Yemen (South Yemen) 1994. Peace Research Institute Frankfurt. Recuperado de http://www.hsfk.de/fileadmin/HSFK/hsfk_publikationen/Yemen-South-Yemen-1994.pdf 
Hill G. \& Nonneman G. (2011). Yemen, Saudi Arabia and the Gulf States: Elite Politics, Street Protests and Regional Diplomacy. London: Chatham House. Hill, G., Salisbury, P., Northedge, L. \& Kinninmont, J. (2013). Yemen: Corruption, Capital Flight and Global Drivers of Conflict. Chatham House Report (Septiembre). Recuperado de http:/ /www.chathamhouse.org/sites/files/ chathamhouse/public/Research/Middle\%20East/0913r_yemen.pdf

Hoffman, S. (1986). Hedley Bull and his Contribution to International Relation. International Affairs, 62 (2), 175-195.

International Republican Institute. (s.f.) Yemen's 1993 Elections: IRI PreElection Assessment, January 1993. Al Bab. Recuperado de http:// www.al-bab.com/yemen/pol/iri0.htm

Inter-Parliamentary Union. (s.f.) Yemen. Parliamentary Chamber: Majlis Annowab. Recuperado de http://www.ipu.org/parline-e/reports/ arc/2353_93.htm

Ismael, S. \& Ismael, T. (2013). The Arab Spring and the Uncivil State. Arab Studies Quarterly, 35 (3), Special Issue: Perspectives on the Arab Uprisings, 229-240.

Ismail, S. (2014). Unification in Yemen: Dynamics of Political Integration 1978-2000. The Civil War. Unpublished Thesis University of Oxford. Recuperado de http://users.ox.ac.uk/ metheses/Ismail\%20Thesis.pdf Jaguaribe, H. (1979). Autonomía periférica y hegemonía céntrica. Estudios Internacionales, (46), 91-130.

Jaguaribe, H. (1998). La relación Norte-Sur. Estudios Internacionales, 21 (84), 425-438.

Jerome, D. (2010). Countering the Threat from Yemen. Interview with Falkenrath, Richard. Council on Foreign Relations. Recuperado de http:/ / www.cfr.org/terrorism/countering-threat-yemen/p23338

Jhonsen, G. (2012). Losing Yemen. Foreign Policy. Recuperado de http:/ / www.foreignpolicy.com/articles/2012/11/05/losing_yemen

Katz, M. N. (1992). Yemeni Unity and Saudi Security. Middle East Policy, 1 (1), 117-135.

Keohane, R. \& Nye, J. (1981). Transnational Relations and World Politics. Massachusetts: Harvard University.

Keohane, R. \& Nye, J. (1987). Power and Interdependence Revisited. International Organization, 41 (4), 725-753. 
Khashoggi, J. (2014). Saudi Arabia and the Houthis. Al Arabiya. Recuperado de http://english.alarabiya.net/en/views/news/middleeast/2014/10/02/Saudi-Arabia-and-the-Houthis.html

Kim, T. (2009). The Sources of Insecurity in the Third World: External or Internal? WIAS, (7). Recuperado de https://www.waseda.jp/wias/ eng/achievement/dp/data/dp2008007.pdf

Knudsen, T. B. (2013). The Master Institutions of International Society: Theorizing Continuity and Change. Paper, 8th Pan-European Conference on International Relations, (18), 21.

Krasner, S. (1981). Transforming International Regimes: What the Third World Wants and Why? International Studies Quarterly, 25 (1), 119-148. Kupchan, C. (2014). Re-Ordering Order: Global Change and the Need for a New Normative Consensus. En Flockhart, T., Kupchan, C., Lin, C., Nowak, B., Quirk, P. y Xiang, L. Liberal Order in a Post-Western World. Washington: Transatlantic Academy, pp. 2-12.

Lees, N. (2012). The Dimensions of the Divide: Vertical Differentiation, International Inequality and North-South Stratification in International Relation Theory. Cambridge Review of International Affairs, 25 (2), 209-230. Lefebvre, H. (2003). Space and the State. En Jessop, M., Brenner, N., Jones, M. y Macleod, B. State/Space. Massachusetts: Blackwell Publishing, pp. 84-101.

Longley, A. (2007). The High Water Mark of Islamist Politics?: The Case of Yemen. Middle East Journal, 61 (29), pp. 240-260.

López, R. (2012). Yemen: geopolítca y revolución. En Mesa, L., El pueblo quiere que caiga el régimen: protestas sociales y conflictos en África del norte y en el Medio Oriente. México D. F.: El colegio de México, pp. 439-456.

Mann, M. (2006). El poder autónomo del Estado: sus orígenes, mecanismos y resultados. Relaciones Internacionales, 0 (5). Recuperado de http://www. relacionesinternacionales.info/ojs/article/view/49.html

Mantzikos, L. (2011). Somalia and Yemen: The Links Between Terrorism and State Failure. Digest of Middle East Studies, 20 (2), 242-260.

Marcuse, H. (1993). El hombre unidimensional. Ensayo sobre la ideología de la sociedad industrial avanzada. Barcelona: Planeta-Agostini.

Marín, R. (2012). Política y represión en el Medio Oriente y el norte de África: dos importantes causas de las manifestaciones actuales. En Mesa, L., El pueblo quiere que caiga el régimen: protestas sociales y conflictos en Africa del norte y en el Medio Oriente. México D. F.: Colegio de México. 
Migdal, J. (2008). Estudiar el Estado. Relaciones Internacionales, 0 (8). Recuperado de http://www.relacionesinternacionales.info/ojs/article/ view/110.html

Walter, M. (2003). La colonialidad a lo largo y ancho: el hemisferio occidental en el horizonte colonial de la modernidad. En Lander, E. (Comp.), La colonalidad del saber: eurocentrismo y ciencias sociales. Perspectivas latinoamericanas. Buenos Aires: CLACSO.

Milanovic, B. (2006). Global Income Inequality: What it is and Why it Matters? UN Department of Economic and Social Affairs. Recuperado de http://www.un.org/esa/desa/papers/2006/wp26_2006.pdf

Miller, P. (2013). Armed State Building Confronting State Failure, (1898-2012). Nueva York: Cornell University Press.

Mols, M. (2011). The State in the Third World. KAS International Reports (November), 119-150. Recuperado de http:/ /www.kas.de/wf/en/33.29406/

National Review (1994). All You Need to Know about South Yemen. National Review, 38 (20).

Nohlen, D., Grotz, F., \& Hartmann, C. (Eds.). (2001). Elections in Asia and the Pacific: A Data Handbook: Volume I: Middle East, Central Asia, and South Asia. Oxford: Oxford University Press.

O'neill, B. (2009). The World Can no Longer Afford to Ignore Yemen's Internal Convulsion. The Daily Star. Recuperado de http://www. huffingtonpost.com/entry/5-humanitarian-crises-we-can-no-longerafford-to-ignore_us_5671956be4b0688701dbc53e

Parker, C. (2004). Sobre la política exterior iniciando el siglo XXI. Revista de Sociologia, (18), 144-157.

Parodi, C., Rexford, E. \& Van Wie, E. (1994). The Silent Demise of Democracy: The Role of the Clinton Administration in the 1994 Yemeni Civil War. Arab Studies Qarterly, 16 (4), 65-76.

Peterson, S. (2000). Is Yemen a Conduit for Global Terrorism? The CS Monitor. Recuperado de http:/ /www.csmonitor.com/2000/0331/p1s3.html

Quijano, A. (2007). Colonialidad del poder y clasificación social. En CastroGómez, S. y Grosfoguel, R. (Comps.). El giro decolonial: Reflexiones para una diversidad epistémica más allá del capitalismo global. Bogotá: Siglo del Hombre.

Quirk, P. (2014). Calibrating U.S. and European Development Aid for the Reshaping World Order. En Flockhart, T., Kupchan, C., Lin, C., 
Nowak, B., Quirk, P. y Xiang, L. Liberal Order in a Post Western World. Washington D. C.: Transatlantic Academy, pp. 39-50.

Rodríguez, O. (2012). Hoy muero yo. Las revueltas en el mundo árabe. Barcelona: Debate.

Rodrik, D. (2012). Who Needs the Nation-State? Economic Geography, 89 (1), 1-19.

Rosenau, J. (1990). Turbulence in World Politics. A Theory of Change and Continuity. Nueva Jersey: Princeton University Press.

Saeed, A. (2012). General Mohamed Ali Mohsen Talks to Yemen Times. Yemen Times. Recuperado de http://www.yementimes.com/en/1571/ intreview/834/General-Mohamed-Ali-Mohsen-talks-to-YemenTimes.htm

Saul, M. (2012). The Search for a Legal Concept of Democracy: Lessons From the Post-Conflict Reconstruction of Sierra Leone. Melbourne Journal of International Law, 3 (1). Recuperado de http:/ / papers.ssrn. $\mathrm{com} / \mathrm{sol3} /$ papers.cfm?abstract_id=1959917

Scholte, J. (2000). Globalization, a Critical Introduction. Nueva York: PalgraveMacmillan.

Sharp, J. (2012). Yemen: Background and U.S. Relations. Congressional Research Service (November). DIANE Publishing. Recuperado de http:/ / www.fas.org/sgp/crs/mideast/RL34170.pdf

Skocpol, T. (1979). State and Social Revolutions: A Comparative Analysis of France, Russia and China. Cambridge: Cambridge University Press.

Skocpol, T. (1985). Bringing the State Back In. Cambridge: Cambridge University Press.

Slater, D. (2008). Re-pensando la geopolítica de conocimiento: reto a las violaciones imperiales. Tabula Rasa, (8), 335-358.

Strang, D. \& Meyer, J. W. (1993). Institutional Conditions for Diffusion. Theory and Society, 22 (4), 487-511.

Tickner, A. B. (2007). Intervención por invitación: Claves de la política exterior colombiana y de sus debilidades principales. Colombia Internacional, (65), 90-111.

Tilly, C. (2005). Democratización mediante la lucha. Sociológica, (57), 35-59.

Tilly, C. (2006). Guerra y construcción de Estado como crimen organizado. Relaciones Internacionales, $O$ (5). Recuperado de http://www.relacionesinternacionales.info/ojs/article/view/52.html 
Unification of Yemen: Joint Security Agreement. (1990). Al Bab. Recuperado de http://www.al-bab.com/yemen/unity/unif7.htm

Unification of Yemen: The Cairo Agreement. (1972). Al Bab. Recuperado de http://www.al-bab.com/yemen/unity/unif1.htm

Unification of Yemen: The Tripoli Agreement. (1972). Al Bab. Recuperado de http://www.al-bab.com/yemen/unity/unif2.htm

United Nations Department for Social and Economic Affairs -PNUD(2011). Assessing Development Strategies to Achieve the MDGs in The Republic of Yemen: Country Study. Recuperado de http://www. un.org/en/development/desa/policy/capacity/output_studies/ roa87_study_yem.pdf

UN-Peacekeeping. (s.f.) Peace and Security. United Nations. Recuperado de http://www.un.org/en/peacekeeping/operations/peace.shtml

Wallerstein, E. (2005). Análisis de sistemas-mundo: Una introducción. México D. F.: Siglo XXI Editores.

Wallerstein, E. (2007). Crisis estructural del capitalismo. Bogotá: Ediciones Desde Abajo.

Walker, R .B. Y. (2012). Sobre las condiciones espaciotemporales en la práctica democrática. Relaciones Internacionales, 0 (19). Recuperado de http:/ / www.relacionesinternacionales.info/ojs/article/view/337/289.html

Waltz, K. (1979). Theory of International Politics. Berkeley: Mc Grow Hill.

Weir, P. (1997). A Clash of Fundamentalism: Wahhabism in Yemen. Middle East Report, (204), 22-26.

Wendt, A. (1992). Anarchy is What State Make of It: The Social Construction of Power Politics. International Organization, 46 (2), 391-425.

Whitaker, B. (1994). Five Scuds Fired at Yemeni Capital as War Worsens. The Guardian. Recuperado de http://www.al-bab.com/yemen/artic/ gdn13.htm

Widmajer, B. \& Seabrooke, L. (2007). Exogenous Shocks or Endogenous Constructions? The Meanings of Wars and Crises. International Studies Qarterly, 51 (4), 747-759.

Xia, L. (2010). Regional Factors in Yemen's Reunification. Journal of Middle Eastern and Islamic Studies (in Asia), 4 (4), 102-120.

Yafai, Y. (2006). Behind the Al Qaeda Jail break. AntiWar. Recuperado de http:/ / www.antiwar.com/orig/yafai.php?articleid $=8608$ 